\title{
What's in it for me? Incentive compensation in hospital medicine
}

\author{
A. Charlotta Weaver, Nita Kulkarni, Rachel Cyrus \\ Division of Hospital Medicine, Northwestern University Feinberg School of Medicine, Chicago, United States
}

Received: December 29, 2017

Accepted: February 12, $2018 \quad$ Online Published: March 15, 2018

DOI: $10.5430 /$ jha.v $7 \mathrm{n} 2 \mathrm{p} 18$

URL: https://doi.org/10.5430/jha.v7n2p18

\begin{abstract}
Objective: Though salary models vary, a portion of physician compensation is often provided as a bonus, or incentive payment, based on clinical productivity measured by the relative value unit (RVU). However, many hospitalists are involved in activities beyond clinical work, either administrative or educational, that may be difficult to measure and recognize in bonus payments. Furthermore, the changing nature of physician and hospital reimbursement necessitates a focus on quality measures not incentivized in the traditional RVU model.

Methods: The authors describe a compensation model in an academic hospital medicine program that was initially developed in 2010 and modified in 2013. The model incents clinical productivity and adherence to quality metrics while also promoting nonclinical academic and administrative activities.

Results: Implementation of this compensation model impacted the division's quality goals by increasing completion of discharge summaries, reconciliation of discharge medications, and placement of follow-up appointment orders upon discharge. The impact on clinical and academic productivity is less clear.

Conclusions: A compensation model that accounts for academic productivity and quality goals along with clinical productivity may be useful in incentivizing hospitalists in both academic and community-based hospital medicine practices. Future work should focus on whether such a model can be used effectively to address additional targets such as reducing readmissions and preventing hospital-acquired conditions.
\end{abstract}

Key Words: Incentive compensation, Incentive payment, Physician, Hospital medicine, Salary, Quality metrics, Relative value unit

\section{INTRODUCTION}

\subsection{Background}

In hospital medicine practices, the pressure to increase clinical productivity in order to support physician salaries is universally present. The 2016 State of Hospital Medicine report notes that $96 \%$ of hospital medicine groups receive financial support beyond professional fee revenue to cover their group expenses, representing an $8 \%$ increase since 2014. This trend continues despite a corresponding rise in clinical productivity, specifically for academic hospitalists whose median work relative value units (RVUs) increased by $27 \%$ during that same time period. ${ }^{[1]}$ Some of this uptrend in RVUs likely reflects the impact of compensation models incorporating clinical productivity when determining incentive pay, as seen in other specialties. ${ }^{[2]}$ While an increase in patient volume certainly contributes to the bottom line, additional factors have gained importance in the current environment of Medicare reimbursement.

\footnotetext{
*Correspondence: A. Charlotta Weaver; Email: aweaver@nm.org; Address: Division of Hospital Medicine, Northwestern University Feinberg School of Medicine, 211 E. Ontario Street Suite 700, Chicago IL 60611, United States.
} 
The average compensation model for adult hospital medicine groups is composed of $80 \%$ base pay, $15 \%$ productivity, and $5 \%$ performance. ${ }^{[1]}$ For the performance component, there has been a notable rise in patient-centered outcomes such as patient satisfaction, mortality, and readmission rates. ${ }^{[1]}$ Initiatives such as the Value-Based Purchasing program and the Merit-Based Incentive Payment System (MIPS) under the Medicare Access and CHIP Reauthorization ACT (MACRA) mandated by the Centers for Medicare and Medicaid Services (CMS), along with other CMS programs such as the Readmissions Reduction program and the Hospital-Acquired Condition Reduction program, incentivize high-value care for physicians and assign financial penalties to poorly performing physician groups and hospitals. ${ }^{[3,4]}$ Pressure to achieve strong performance on quality measures and fulfill MIPS requirements while simultaneously maintaining or even exceeding clinical productivity goals is increasingly prominent. Moreover, in academic hospital medicine, there exists added pressure of academic productivity related to teaching and research, which may contribute to academic promotion but is not necessarily supported financially. It remains unknown whether a performance-based incentive can motivate academic hospitalists to provide high quality, high volume care while contributing to their group's academic mission.

\subsection{Various physician incentive compensation (IC) mod- els}

Different models compensating nonclinical activities in academic settings have been described. An academic gastroenterology division rewarded non-financial incentives, including additional time and research staff for scholarly activities, to clinicians who exceeded annual RVU targets. ${ }^{[5]}$ This system led to increased clinical and nonclinical productivity for the group. Monetary incentives, however, are more common. An analysis of 31 academic orthopedic surgery departments showed that more than half the programs implemented bonuses for nonclinical work, including teaching effort, committee work, and citizenship, representing a mean of $13 \%$ of total compensation. ${ }^{[2]}$ Similarly, a systematic review of 14 studies examining physician compensation in academic practices described different tracking systems to determine monetary incentives for clinical and nonclinical work. ${ }^{[6]}$ Most found an increase in professional productivity, both clinical and nonclinical, with the use of performancebased compensation systems. Less is known about the effects of IC models in hospital medicine.

\section{METHODS}

\subsection{Description of division of hospital medicine}

Our division is affiliated with a large urban academic medical center and comprised of 78 faculty members with 58 clinical

Published by Sciedu Press full-time equivalents. Overall, the makeup of the group is the following: 59\% female, mean tenure as hospitalist of 5.89 years, and $45 \%$ academic ranking of assistant professor or higher. The individual provider workload does not vary significantly from one hospitalist to another and is determined by a set number of beds that are managed by our division. Hospitalists can earn more clinical RVUs through better documentation, staffing patients on the teaching service on the day of admission, seeing more patients on admitting shifts, and moonlighting extra shifts. In addition to providing direct patient care, faculty teach medical students and residents, engage in quality improvement (QI), hold leadership positions within the hospital and university, and participate in research. The division's IC structure has evolved over several years. Initially it was based on clinical productivity with subjective modifications. In 2010, an IC task force convened to improve transparency and incorporate academic and quality goals. In the new structure, a maximum $15 \%$ of total compensation was divided equally between clinical and academic/administrative productivity. Clinical productivity was calculated using RVUs. Academic/administrative productivity was quantified by a point system tallying faculty-reported work in education, research, administration, and QI. RVUs and points were grouped into quintiles, and IC payment was calculated relative to peers. The actual numerical difference between individual hospitalists' IC remained intentionally small, at less than 5\%. Additionally, penalties were assessed for not meeting two quality metrics: discharge summary and medication reconciliation completion.

\subsection{Development of IC program}

In 2013, IC was modified to improve fairness and simplicity and align with promotions criteria. The $15 \%$ IC was reallocated to $5 \%$ each based on clinical productivity, academic productivity, and quality goals. We simplified the tally system for academic productivity due to administrative burden and lack of fairness in subjective reporting, and then aligned it with promotions criteria to harmonize with our academic institution. Academic/administrative productivity is now rewarded full incentive payment by attaining a baseline minimum of activities that mirror those required for maintenance of current academic appointments and promotions (see Table 1). Five metrics are now represented among the quality goals: discharge summary completion, medication reconciliation completion, placement of follow-up appointment orders, division meeting attendance, and citizenship. One-fifth of the IC quality portion is rewarded for attaining targets in each metric. These five measures were chosen specifically for their relevance to high quality clinical care and group wellness as well as their ability to be attributed accurately to individual physicians. To promote transparency within the 
division, we release monthly scorecards to all hospitalists with each physician's clinical RVU productivity and quality metric percentages. We also maintain an overall division scorecard with group-attributed metrics (e.g., readmission and hospital acquired infection rates), but these measures are not individually scored or reported and have no impact on individual IC.

\section{RESUlts}

\subsection{Targeted IC improves metrics}

The implementation of the revised IC model over the last three years has positively impacted our division's goals, especially the quality metrics. Discharge summary completion improved from $75.9 \%$ to $98.5 \%$ and discharge medica- tion rec-onciliation from $66.4 \%$ to $99 \%$ between 2012 and 2015. Placement of follow-up appointment orders prior to dis-charge improved from $67 \%$ to $81 \%$ between 2014 and 2015 (see Figure 1). The impact on clinical and academic productivity is more difficult to ascertain. Total clinical RVUs for the division have varied without a discernable trend, and we suspect the variance is due to changing census and bed coverage. Differences between individual providers remain minimal. Further, academic productivity is subjective and heavily influenced by reporting disparities. Although we've seen a moderate increase in academic achievements since the implementation of the IC model including a greater percentage of higher academic rankings, this likely reflects the division's maturing faculty rather than a consequence of the IC itself.

Table 1. QI activities that qualify for academic incentive compensation

\begin{tabular}{llll}
\hline Activity & $\begin{array}{l}\text { Incentive } \\
\text { Compensation Points }\end{array}$ & $\begin{array}{l}\text { Contributes to } \\
\text { Reappointment }\end{array}$ & $\begin{array}{l}\text { Contributes to } \\
\text { Promotion }\end{array}$ \\
\hline $\begin{array}{l}\text { Consultative position in government or non-government } \\
\text { organization }\end{array}$ & 2 & yes & $\begin{array}{l}\text { yes, depending on } \\
\text { scope }\end{array}$ \\
$\begin{array}{l}\text { Development and implementation of clinical programs or QI } \\
\text { work (e.g., Team Asthma, Hospitalist workflow }\end{array}$ & $\begin{array}{l}1 \text { if participant } \\
\text { improvements) }\end{array}$ & yes leader & yes, depending on \\
scope \\
$\begin{array}{l}\text { QI project lead, publication and/or award } \\
\begin{array}{l}\text { Participation in guideline development, expert opinion } \\
\text { documents that form standard of care }\end{array}\end{array}$ & 2 & yes & yes \\
$\begin{array}{l}\text { Clinical Coach } \\
\text { First year faculty participation in mentorship program }\end{array}$ & 1 & yes & yes \\
\hline
\end{tabular}

Note. As shown in Table 1, these are quality improvement, faculty development and clinical expertise activities that quality for academic incentive compensation points and their value toward reappointment and promotion to assistant professor. Two points are assigned if activity is more highly supportive of promotion, instead of reappointment only

\section{Discussion}

\subsection{IC necessitates transparency, fairness, and communication}

While IC models can differ greatly, underlying common themes include the need for transparency, fairness, and communication. One study concluded that transparency of productivity metrics using individual scorecards available to all physicians in a surgery practice was associated with increased clinical productivity. ${ }^{[7]}$ Such transparency can add an element of positive peer pressure leading to behavior change. However, financial competition may also negatively impact collaboration and distract physicians from the larger goals of the institution. ${ }^{[8]}$ To prevent unintended consequences of IC, we kept differences in payments to individual physicians small. As a result, we believe that implementation of our IC model and monthly scorecard has motivated faculty to reach quality benchmarks while maintaining expected levels of clinical productivity. Fairness in allocation of resources and communication regarding the process of allocation are also key components of successful incentive models. An academic incentive plan developed by another surgery department aimed to promote productivity in teaching, research, citizenship, and administration by allocating $1 \%$ of net patient collections to faculty based on their nonclinical activities. ${ }^{[9]}$ Half of the faculty surveyed noted that implementation of the plan encouraged them to increase their academic activities, but half also expressed concern about lack of transparency and communication regarding motives and the process of allocating funds. We invited all interested faculty members to join the IC task force and publicized our IC model through multiple communications to emphasize necessity and details of our model.

\subsection{IC impact on motivation}

Studies on motivation show that incentives improve performance on straightforward tasks with achievable goals. ${ }^{[10]} \mathrm{We}$ 
chose metrics that were more process-oriented than outcomeoriented and that can be easily measured and attributed to individual hospitalists. Additionally, in order to promote a positive environment, we chose to give rewards for good performance rather than assign penalties for poor performance. By linking these tasks to IC, we noticed quick trends towards compliance despite lack of previous prioritization by faculty. However, whether such incentives help or hinder creative academic work is debatable. Psychology literature argues that extrinsic rewards such as monetary incentives are harmful to intrinsic motivation. ${ }^{[11]}$ If intrinsic motivation is heightened by a sense of autonomy, mastery, and purpose, then linking creative work to rigid compensation plans may lead to unintentional devaluation or decreased performance by faculty. Assigning points to academic work as we did in our previous model may have counteracted the intrinsic enjoyment and undermined the value of this work. By creating an all-or-none system that rewards physicians for meeting a minimum threshold of academic work, we predicted that faculty would focus on activities they enjoy, while maintaining a sense of choice and purpose. The current IC model also aligns well with other division efforts to encourage personal academic growth, including mentorship programs and numerous opportunities for professional development.

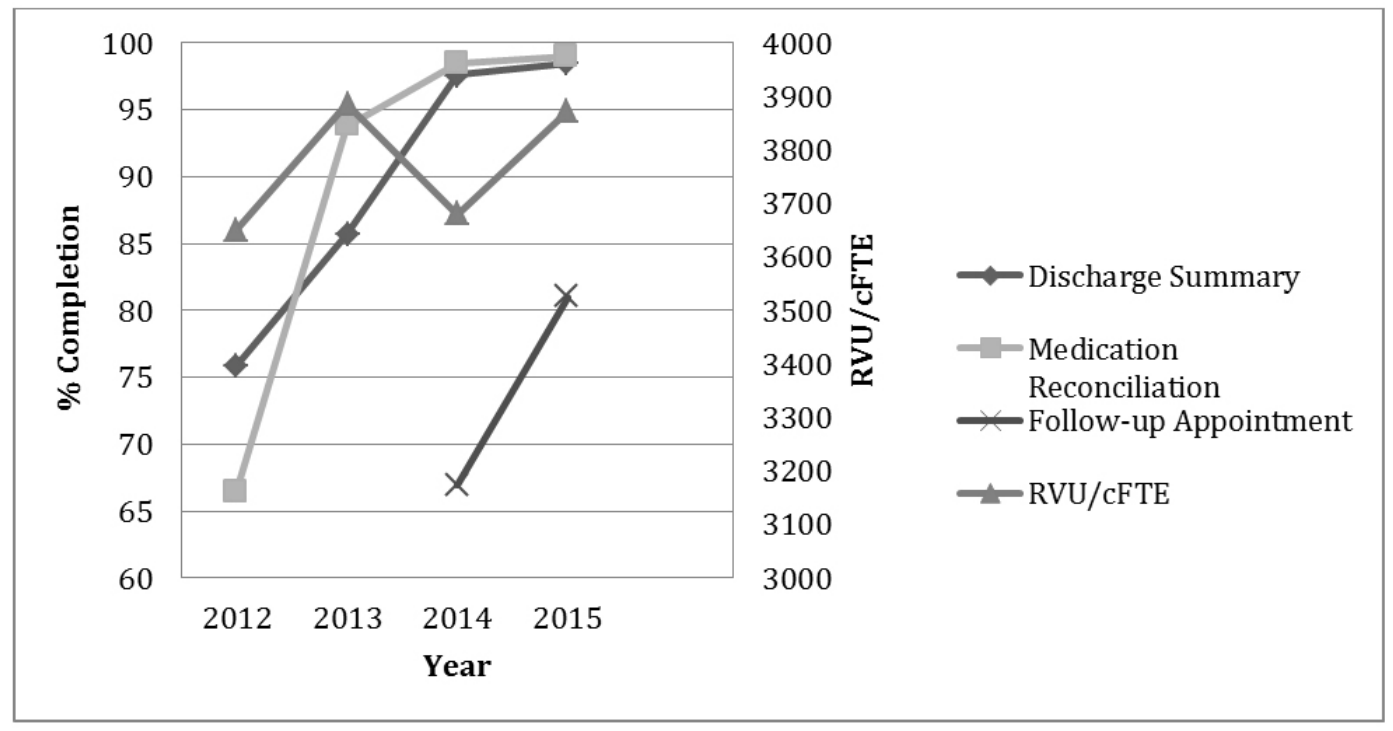

Figure 1. Discharge summaries

This graph displays the percent of faculty completing discharge summaries within 3 days, performing medication reconciliation by discharge, and placing at least one follow-up appointment order by discharge; and annual total RVUs per cFTE. The follow-up appointment measure was added in 2014, and consists of EMR order entry that alerts schedulers to coordinate an outpatient follow-up appointment in the timeframe and specialty indicated by the physician placing the order. Abbreviations: RVU, relative value unit; $c F T E$, clinical full time equivalent; EMR, electronic medical record.

\section{Conclusions}

Compensation models should strive to motivate individual physicians and fairly reward work. By creating a model that promotes achievable goals and emphasizes transparency and fairness, we developed an IC system that incentivizes academic hospitalists to maintain clinical productivity, contribute to academic and administrative efforts, and prioritize quality metrics. These incentives are increasingly important as the ambitious requirements of MIPS are implemented. Moreover, we purposefully kept the numerical difference in IC payments among individual hospitalists small to avoid unnecessary competition. The structure and components of our model can be customized to most practices, including those in community settings, since administrative and QI work are valuable in non-academic settings as well. Future work should focus on how best to engage and incentivize physicians to achieve quality and safety goals such as reducing readmissions rates and hospital-acquired conditions. As we continue to measure the impact of our IC model, we anticipate that it will translate into productive and motivated faculty who will contribute to the overall success of our division and the specialty.

\section{ACKNOWLEDGEMENTS}

Kevin O'Leary MD, MS, Mark Williams MD, McKay Barra, and Emily Stalec.

\section{CONFlicts OF InTEREST Disclosure}

The authors declare they have no conflicts of interest. 


\section{REFERENCES}

[1] State of Hospital Medicine Report. Society of Hospital Medicine. 2016.

[2] Emery SE, Gregory C. Physician incentives for academic productivity. An analysis of orthopaedic department compensation strategies. The Journal of Bone and Joint Surgery. American Volume. 2006; 88(9): 2049-2056. PMid: 16951123.

[3] Blumenthal D, Jena AB. Hospital value-based purchasing. J Hosp Med. 2013; 8(5): 271-277. PMid: 23589485. https://doi.org/ $10.1002 / \mathrm{jhm} .2045$

[4] Rich EC, Reschovsky JD. After the "Doc Fix": Implications of Medicare Physician Payment Reform for Academic Medicine. Academic Medicine: Journal of The Association of American Medical Colleges. 2016; 91(7): 900-903. PMid: 27224297. https: //doi.org/10.1097/ACM.0000000000001242

[5] Brandt TL, Romme CR, LaRusso NF, et al. A novel incentive system for faculty in an academic medical center. Ann Intern Med. 2002; 137(9): 738-743. PMid: 12416947. https://doi.org/10.7326/ 0003-4819-137-9-200211050-00009

[6] Andreae MC, Blad K, Cabana MD. Physician compensation programs in academic medical centers. Health Care Management Re- view. 2006; 31(3): 251-258. PMid: 16877893. https ://doi.org/ 10.1097/00004010-200607000-00011

[7] Scoggins CR, Crockett T, Wafford L, et al. Improving clinical productivity in an academic surgical practice through transparency. Journal of the American College of Surgeons. 2013; 217(1): 46-51; discussion 51-45.

[8] Gunderman RB. The perils of paying academic physicians according to the clinical revenue they generate. Medical Science Monitor. 2004; 10(2): RA15-20. PMid: 14737057.

[9] Mitchell CC, Ashley SW, Orgill DP, et al. Gauging surgeons' understanding and perceptions of an academic incentive plan. Archives of Surgery. 2009; 144(5): 421-426; discussion 426. PMid: 19451483. https ://doi.org/10.1001/archsurg. 2009.47

[10] Pink DH. Drive: the surprising truth about what motivates us. New York, NY: Riverhead Books; 2009.

[11] Deci EL, Koestner R, Ryan RM. A meta-analytic review of experiments examining the effects of extrinsic rewards on intrinsic motivation. Psychological bulletin. 1999; 125(6): 627-668; discussion 692-700. PMid: 10589297. https ://doi.org/10.1037/0033-2 909.125 .6 .627 